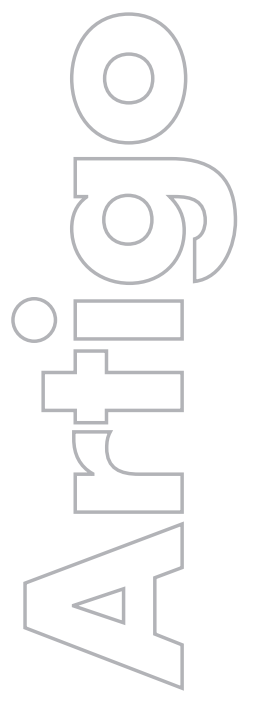

revista

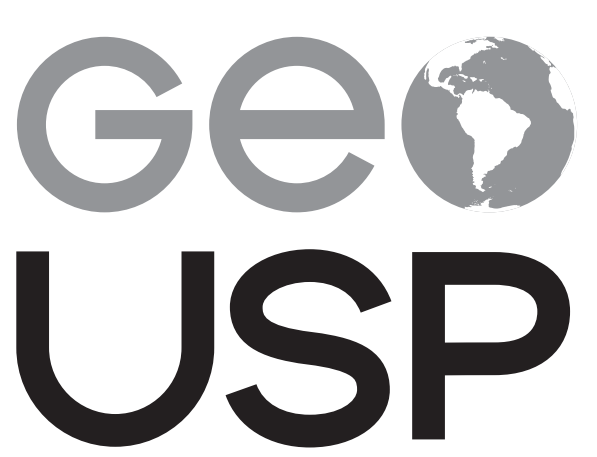

espaço e tempo

Volume 18, no 1 (2014)
As articulações entre comércio e distribuição na dinâmica da produção em aglomerado produtivo calçadista de portugal

\author{
Judite de Azevedo do Carmo \\ Universidade do Estado do Mato Grosso
}

p. $83-96$

Artigo disponível em:

http://www.revistas.usp.br/geousp/article/view/81082

Como citar este artigo:

CARMO, J. A. As articulações entre comércio e distribuição na dinâmica da produção em aglomerado produtivo calçadista de Portugal. GEOUSP - Espaço e Tempo (Online), São Paulo, v. 18, n. 1, p. 83-96, 2014.

\section{$((c))$ EY}

Este artigo está licenciado sob a Creative Commons Attribution 3.0 License. 


\title{
As articulações entre comércio e distribuição na dinâmica da produção em aglomerado produtivo calçadista de Portugal ${ }^{1}$
}

Judite de Azevedo do Carmo

\section{Resumo}

$\bigcirc$ objetivo deste artigo é apresentar os resultados da pesquisa sobre as articulações entre o comércio e a produção em aglomerado produtivo, tomando como espaço empírico São João da Madeira (PT). Para tanto, fizemos leituras de bibliografia teórica e prática brasileira e portuguesa, bem como coleta de dados quantitativos e qualitativos em órgãos oficiais, indústrias e estabelecimentos comerciais do município, por meio de entrevistas e aplicação de questionários. A análise dos dados obtidos permitiu constatar que os calçados de produção local são valorizados pelos comerciantes, sendo comercializados em todos os estabelecimentos, embora não se tenha verificado intensa relação entre os produtores e os comerciantes locais.

Palavras-chave: Aglomerados produtivos. Produção. Comércio. Setor calçadista. Portugal.

\section{Trading articulations and production in agglomerated productive shoes in Portugal}

\begin{abstract}
The purpose of this article is to present the results of the research about the articulations between the trade and the production in agglomerated productive, having as an empirical space São João da Madeira (PT). To work on that, we read theoretical and practical bibliographies, both Brazilian and Portuguese and also collected quantitative and qualitative data in official bodies, as well as in industries and commercial establishments in the city. It was identified the shoes that were
\end{abstract}

1 Pesquisa elaborada com apoio financeiro da Capes. 
fabricated in the local area are valued by the traders because all the researched establishments sell shoes fabricated locally, even if the relationship between the producers and the local traders is not so intense.

Keywords: Agglomerated productive. Production. Trade. Footwer sector. Portugal.

\section{Introdução}

$\bigcirc$ esgotamento do modelo de acumulação fordista proporcionou o surgimento de outro modelo, o pós-fordista ou de acumulação flexível. No entanto, é importante salientar que o surgimento de um não representa o final do outro. Assim uma "reestruturação do sistema industrial que permite a coexistência de diferentes sistemas de produção: em alguns setores a produção em grande escala continua, com maior diferenciação da produção, enquanto em outros predomina o modelo de especialização flexível" (Rovere, 1999, p. 145). Nesta perspectiva, como assinala Mendes (1997, p. 44), a atividade industrial tem sido alvo de grandes mudanças estruturais e organizacionais, principalmente a partir dos anos de 1970.

Em relação às mudanças na atividade industrial, Maia (1995, p. 137) coloca que as indústrias de vários setores vêm adotando estruturas produtivas mais flexíveis, inclusive aquelas mais tradicionais. Diante disso, em certas regiões, é possível a verificação da formação dos chamados distritos industriais ou redes de indústrias com o principal objetivo de enfrentar a crise derivada do esgotamento do modelo de acumulação fordista. Como se vê, a produção tem se organizado no espaço de diversas formas, dentre as quais podemos citar os distritos industriais, os clusters, polos e Arranjos Produtivos Locais, cada qual com suas especificidades que não serão tratadas aqui, uma vez que esse debate não consta do objetivo deste trabalho; portanto, a concentração geográfica de indústrias será denominada genericamente como aglomerado produtivo, sem entrarmos em suas especificidades.

Pinheiro (1993, p.17) explica que a concentração geográfica constitui-se em uma estratégia que as empresas de produção "flexível" adotaram com a intenção de reduzir os custos e as dificuldades de suas transações, e de certa forma maximizar seu acesso ao contexto cultural de informação do sistema de produção. Isto é possibilitado pelas economias externas que geram.

Para as MPMEs (Micros, Pequenas e Médias Empresas), a concentração em aglomerações produtivas é um recurso utilizado para ultrapassarem os obstáculos que lhes são impostos devido a seu reduzido tamanho, pois através das associações existentes dentro do aglomerado é possível, para essas unidades industriais, simularem o funcionamento das grandes indústrias (Garcia; Costa, 2005, p. 29).

Como discorrido nos parágrafos anteriores, a atividade industrial passou por grandes transformações a partir dos anos de 1970; estas, porém, não foram verificadas somente na produção, mas em toda a cadeia de valor, ou seja, desde a concepção do produto até seu consumo final.

$\bigcirc$ comércio realizado em diferentes estruturas, de acordo com Barata Salgueiro e Cachinho (2006, p. 3), possui como principal objetivo disponibilizar as mercadorias aos consumidores (empresas ou cidadãos), de modo a satisfazer necessidades e desejos. Portanto, ele é condicionado, na sua organização e funcionamento, pelas alterações no sistema de produção, pela distribuição das populações e pelas mudanças em seu estilo de vida, o que acaba por interferir nos hábitos de consumo. 
comércio varejista realiza-se em diferentes estruturas comerciais como as lojas especializadas, grandes magazines, mercados populares, lojas de autosserviço, supermercados e hipermercados, shoppings centers, lojas de conveniência, galerias, lojas de departamento, entre outras. Essas estruturas comerciais, de acordo com Carreiras (1999, p. 89), constituem o lugar onde ocorre a materialização do consumo, podendo, portanto, ser chamado de espaço de consumo.

Para Pintaudi (1981, p. 15), o consumo "é um processo através do qual um valor de uso é gasto, é destruído, para satisfazer uma necessidade qualquer". Porém, sendo a mercadoria constituída de valores simbólicos, o consumo vai além da simples satisfação dos desejos, ele se torna uma forma de comunicação (Baudrillard, 1981). Por isso que, na atualidade, a publicidade, o marketing e até mesmo a forma como as mercadorias são expostas nas diversas estruturas do comércio seguem a lógica da "mercadoria signo e dão novos significados aos bens de consumo que assim, associam-se ao luxo, à beleza, ao exotismo e à fantasia" (Cleps, 2005, p. 81).

Nessa perspectiva, de acordo com Cachinho (2002, p. 168), "o consumidor torna-se um verdadeiro actor e o consumo uma manifestação simbólica e comunicacional”. $\bigcirc$ mesmo autor ainda salienta que "o poder simbólico do consumo diz tanto respeito às mercadorias como aos lugares erigidos em seu nome", ou seja, aos diferentes espaços de consumo.

Diante dessa nova realidade, os industriais começaram a estreitar as suas relações com os agentes de comércio e de distribuição, procurando identificar as necessidades dos consumidores para poderem atuar com eficácia e de forma competitiva na oferta de produtos e, assim, obter maiores resultados junto aos diversos mercados. Os aglomerados produtivos, entendidos como propulsores de desenvolvimento local e regional, não podem ficar de fora desse movimento, eles necessitam, por meio de sua governança, desenvolver um setor de distribuição e de comércio de forma estruturada e que funcione como verdadeiro interlocutor, possibilitando ao aglomerado atuar na elaboração do produto que condiz com as necessidades e desejos dos consumidores finais.

Apesar de detectada a importância dos processos finais e iniciais da cadeia produtiva, verificamos que pouca atenção thes tem sido dirigida nos estudos acadêmicos realizados sobre aglomerados produtivos, sendo que, muitos deles focaram-se nas relações produtivas, na governança, na mão de obra etc. Em relação ao comércio e ao consumo, percebemos que indiretamente eles têm aparecido em alguns estudos; porém, entendemos que o fato da dinâmica do comércio e do consumo terem sido deixados em segundo plano, tem gerado uma lacuna teórica, pois o comércio é o meio pelo qual se realiza a acumulação do capital. Portanto, apoiados nas obras dos autores citados, os quais nos proporcionaram o respaldo teórico para o entendimento do tema pesquisado e na análise empírica foi-nos possível enfocar, nesta pesquisa, a distribuição e o comércio na dinâmica da produção do aglomerado produtivo de São João da Madeira (PT).

Para compreender as articulações do comércio, na dinâmica da produção em São João da Madeira, adotamos uma metodologia de pesquisa com base em coleta de dados quantitativos e qualitativos em órgãos oficiais e de atuação na governança do aglomerado, assim como em indústrias e em estabelecimentos comerciais do município, por meio de entrevistas e aplicação de questionários.

\section{Caracterização do setor calçadista de Portugal}

O setor calçadista português é considerado um setor dinâmico e de grande importância para o desenvolvimento econômico do país, contando com aproximadamente 1354 indústrias em 2010, com uma produção em torno dos 61.543 milhares de pares e com o emprego de 32.510 trabalhadores 
(Apiccaps- Associação Portuguesa dos Industriais de Calçados, Componentes e Artigos de Pele e seus Sucedâneos-, 2011). O Gráfico 1 apresenta a evolução do número de indústrias de calçado em Portugal.

\section{Gráfico 1}

\section{Evolução do número de indústrias de calçados de Portugal de 1974 a 2010}

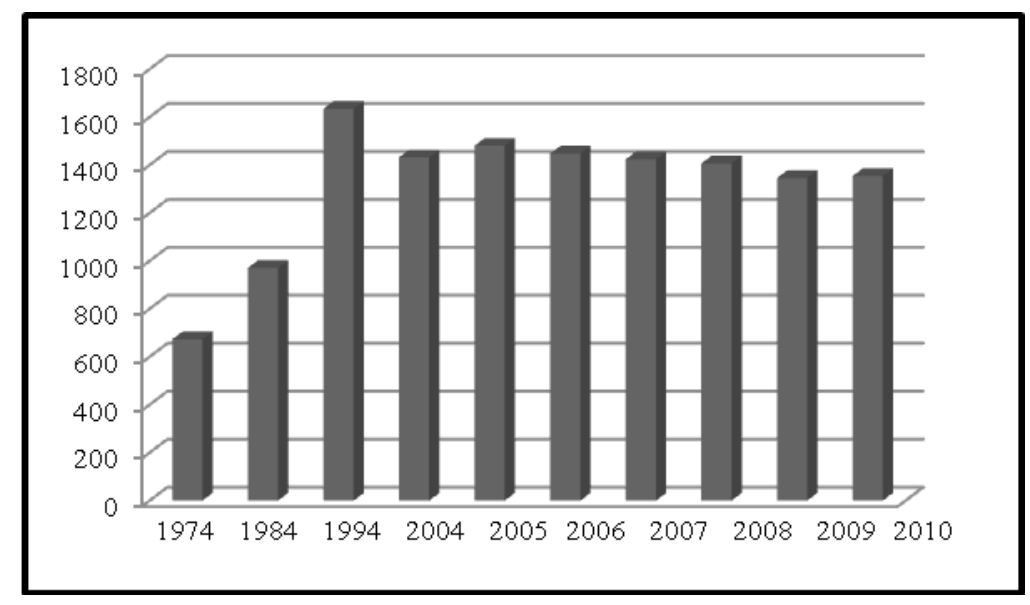

fonte: Apiccaps (2011). Organizado pela autora.

A indústria calçadista portuguesa, que vinha apresentando crescimento nas décadas de 1970 a 2000, com a intensificação da concorrência internacional, teve de optar por outras estratégias competitivas. Várias das grandes empresas de capital estrangeiro decidiram-se por não participar dessa empreitada e optaram pela migração em direção a outros países, onde puderam continuar com o mesmo fator de competitividade (baixo custo de produção). Tal migração foi facilitada pela integração de novos Estados-membros na União Europeia, com vantagens de custos significativas, os quais se tornaram alternativos para os investimentos estrangeiros. Algumas empresas nacionais, não sendo capazes de se manter perante a acirrada concorrência e nem de se adaptar aos novos modelos de competição, acabaram por sucumbir pelo caminho (Apiccaps, 2011).

Outro fato de impacto nas indústrias calçadistas portuguesas foi a adoção do euro como moeda comum, eliminando "a possibilidade de desvalorização da moeda nacional que, nomeadamente na década de 1980, teve um papel relevante na defesa da competitividade das exportações portuguesas" (Apiccaps, 2011).

A indústria, para responder aos novos desafios impostos, segundo a Apiccaps, procedeu a uma reestruturação e reorientação estratégica, principalmente no que tange a reengenharia dos processos de produção, podendo então responder a encomendas de apenas algumas unidades, desta forma mostrando-se mais flexível diante das necessidades dos clientes.

Sobre a questão da adoção de novas tecnologias e inovação no setor calçadista, Vale e Caldeira (2007, p. 535), baseados em estudos de Fonseca et al. (2001), argumentam que a produção de calçados tem adotado, no decorrer dos anos, várias inovações tecnológicas, passando algumas etapas da produção a serem realizadas por computador, como por exemplo, a concepção e o design. Houve também a adoção de equipamentos de corte a laser etc. A adoção dessas novas tecnologias foi uma 
medida encontrada pela indústria de calçado como forma de responder às exigências dos mercados mais desenvolvidos que demonstraram preferências de consumo de calçados, que trazem um maior conforto, advindo, daí, a preocupação com os atributos técnicos e com a qualidade do material utilizado.

Os estudos que focam de modo geral a indústria calçadista portuguesa colocam que esta possui forte vocação exportadora. Tal vocação parece estar sendo reforçada, como nos indica os dados de exportação disponibilizados pela Apiccaps. Em 2005 o volume exportado representou 88\% do total das exportações de calçados. Já em 2010, o volume exportado chegou a 68.133 milhões de pares, o que representa $95 \%$ do total da produção. Os principais destinos geográficos dos calçados produzidos em Portugal estão indicados na Tabela 1.

\section{Tabela 1}

\section{Principais destinos geográficos das exportações de calçados de Portugal em 2010}

\begin{tabular}{cc}
\hline destino geográfico & percentual \\
\hline Europa & 96 \\
\hline América & 1,6 \\
\hline Ásia & 1,2 \\
\hline África & 1,1 \\
\hline Oceania & 0,3 \\
\hline
\end{tabular}

fonte: Apiccaps (2011). Organizada pela autora.

Dentro da Europa, destacam-se cinco mercados, pois juntos absorvem 80\% das exportações destinadas a esse continente, são eles: França, Alemanha, Holanda, Espanha e Reino Unido. É importante ressaltar que as exportações para a Espanha tiveram entre 2000 e 2005 um acréscimo significativo de 51\%, "a proximidade geográfica e a dimensão de mercado sugerem que este é ainda um mercado com potencial de crescimento" (Apiccaps, 2011).

De acordo com estudo da Apiccaps, na década de 1990, as exportações de calçado cresceram mais rapidamente do que as importações, gerando um aumento significativo do excedente comercial. Para a ocorrência desse aumento, as empresas de capital estrangeiro tiveram grande participação no ano de 2000, pois elas representavam 40\% das exportações nacionais. Os primeiros anos da década de 2000 foram de grande impacto para as exportações portuguesas de calçado, com o encerramento da maior parte das grandes indústrias de capital estrangeiro, acrescentando-se a concorrência do calçado de origem asiática, nos principais mercados, assim as exportações caíram de 2001 a 2005 a quase 30\%.

A partir de 2005, as exportações voltaram a crescer, porém a evolução do crescimento das exportações foi interrompida já em 2009, uma vez que a indústria calçadista não ficou ilesa à crise econômica internacional de 2009. Contudo mostra sinais de recuperação em 2010.

A indústria de calçados de Portugal, como já dissemos em linhas anteriores, está direcionada em seus quase $100 \%$ ao mercado externo, porém o consumo de calçados no mercado interno ficou na casa dos 60 milhões de pares em 2010, valor equivalente a produção nacional (dados da Apiccaps). Esses dados nos instigam aos seguintes questionamentos: $\bigcirc$ mercado português de calçado é abastecido por quais produtores? Por que tão pouco do volume produzido nacionalmente fica no país? 
Os principais fornecedores de calçados para Portugal, de acordo com a Apiccaps (2011), são a Espanha e a China, ficando esses dois países com valores acima dos 20 milhares de pares. É interessante notar que a Espanha é o principal parceiro comercial de Portugal, pois também se configura entre os cinco principais destinos geográficos dos calçados portugueses. Neste momento é de grande relevância lembrar a colocação da Apiccaps de que boa parte das importações originadas da Ásia possui país europeu como intermediário, como a Holanda, por exemplo.

Para obter resposta à segunda questão precisamos conhecer o mercado português e as especificidades do calçado produzido nesse país. A indústria portuguesa de calçado apresenta uma forte especialização na produção de calçado de couro, que possui valor acrescentado mais elevado. Em 2010, 4 em cada 5 pares produzidos foram feitos à base desse material (Apiccaps, 2011). Dessa forma, o calçado português, em sua maior parte, possui alto valor agregado, atendendo, portanto, os mercados mais exigentes e de maior rendimento médio; em contrapartida, as importações em Portugal são de calçados produzidos com outros materiais e de valor reduzido. Dados da Apiccaps apontam para o aumento entre 2005 e 2010 do consumo de calçados em têxtil e plástico, passando dos 47\% para $77 \%$. O calçado impermeável também apresentou um aumento de $20 \%$ para o período, enquanto os calçados de couro apresentaram aumento muito inferior com um percentual em torno de 7\% e 6\%.

$\bigcirc$ amplo aumento da busca por calçados de valor reduzido pode ser explicado pela quase estagnação econômica na última década, o que travou o dinamismo do consumo do país. Diante de tal cenário, a população dirigiu-se para os segmentos de produtos de valor reduzido. Um dos fatores que explicam esta estagnação econômica é a deslocalização das indústrias estrangeiras que lá estavam e que chegaram a ser responsáveis por cerca de um quarto do emprego setorial; portanto, houve grande redução de emprego no setor. Essa redução de emprego foi percebida posteriormente também em outros setores, de modo a diminuir o poder de compra da população (Apiccaps, 2011).

Os dados de 2010, referentes à conjuntura industrial (produção e exportação), parecem indicar uma pequena melhora, contudo ainda há que se ter cautela para avaliar essa situação a longo prazo, pois, em 2010, o PIB de Portugal registrou crescimento de 1,4\%, valor este que ficou abaixo do PIB mundial, cujo crescimento se deu na ordem de 5,5\% e o da União Europeia apresentou crescimento de 1,8\% (Apiccaps, 2011).

Diante desse estado de estagnação econômica, a procura por produtos de baixo valor é reforçada. Assim sendo, tiveram maior evolução no mercado português os calçados que apresentavam tais características, como os chineses, por exemplo.

A indústria calçadista portuguesa ainda está atravessando um momento difícil, embora pareça estar começando a dar sinais de melhora. $\bigcirc$ calçado produzido em Portugal, na maior parte tem o couro como a principal matéria-prima, sendo destinado aos principais mercados europeus. As exportações são, portanto, extremamente concentradas, assim como as importações de calçados, que possuem como principal origem a Espanha, porém com grande participação da China, um país fora do continente europeu. A Apiccaps procura desenvolver iniciativas e estratégias para avançar em direção a outros mercados, mas as forças convergem para o mercado regional. A integração ao mercado único, com a adoção da moeda única, somada ainda a proximidade geográfica, são fatores que favorecem essa concentração. 


\section{A produção de calçados em São João da Madeira (PT)}

A produção de calçados em Portugal, segundo o INE (Instituto Nacional de Estatística), está concentrada na região norte do país (Figura 1), nas sub-regiões Ave, Tâmega e Entre Douro e Vouga. Nas duas últimas, ela assume maiores proporções, mas não são todos os municípios pertencentes a essas regiões que desenvolvem a produção de calçados. Em Ave, verifica-se a produção em Vizela e Guimarães, em Tâmega, ela é realizada em Felgueiras e Lousada e no Entre Douro e Vouga, destacamse São João da Madeira, Santa Maria da Feira, Oliveira de Azeméis e Arouca. A explicitação desses municípios, como produtores de calçados, não implica dizer que a produção não ocorra em outros, porém a importância da atividade nestes outros locais é menor.

\section{Figura 1}

\section{Localização das regiões onde se concentra a produção de calçados de Portugal}

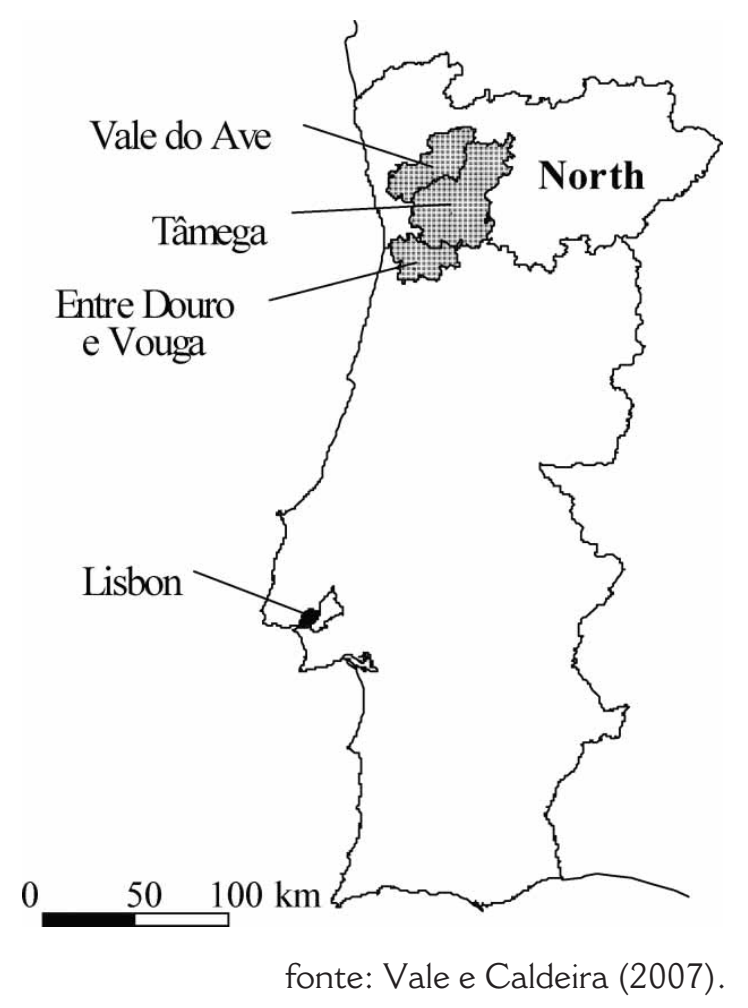

Como os dados do INE indicam, a sub-região de Entre Douro e Vouga possui maior número de municípios que desenvolvem a atividade de produção de calçados, mas em número de trabalhadores ela perde para a sub-região do Tâmega, sendo que os dados de trabalhadores, por município, para 2009, indicaram 10.912 e 11.645, respectivamente.

A literatura que trata do setor de calçado de Portugal evidencia os municípios de Felgueiras e São João da Madeira como os principais aglomerados produtivos, portanto para decidirmos em qual dos dois realizar a verificação em campo, procuramos, por meio de fontes bibliográficas, verificar as características de cada um e depois compará-los.

Em Felgueiras, a produção é recente, com uma estrutura industrial cuja dimensão das unidades produtivas é maior. Há um emprego de equipamentos e tecnologias mais avançados e entre os empresários do setor verifica-se um evidente espírito empreendedor. A mão de obra é menos intensiva, o volume da produção diária é alto, a qualidade do produto é inferior, a maior parte dos calçados 
fabricados é informal, destacando em maior porcentagem o calçado masculino, sendo que o preço do calçado deste município é inferior em relação ao de São João da Madeira e o destino da produção é o mercado externo, em segmentos inferiores (Eiriz; Barbosa, 2007, p. 35).

Em São João da Madeira, município que possui tradição na fabricação do calçado, a produção é antiga, as unidades industriais são em grande maioria, de dimensões menores. A tecnologia e os equipamentos utilizados na produção são menos avançados, não é muito evidente o espírito empreendedor. Há o emprego de mão de obra mais intensiva, o volume produzido diariamente é baixo, os calçados produzidos na maior porcentagem são os de senhora e o formal. A qualidade é elevada e o preço também. Sua produção atende a segmentos superiores do mercado externo e interno (Eiriz; Barbosa, 2007, p. 35).

Diante das características dos dois municípios, decidimos trabalhar em terreno com o de São João da Madeira, pois o objetivo do estudo é verificar as articulações entre a distribuição e o comércio, no âmbito da produção de calçados, sendo que neste município a produção é destinada ao mercado interno e ao externo; portanto, teremos elementos de análise da distribuição nos dois mercados. Além disso, o fato de o setor de calçados ter-se desenvolvido em torno de tal município, isto o faz tradicional nessa atividade, pois esse fator também contribuiu para a sua adoção como universo espacial empírico.

A cidade de S. João da Madeira localiza-se na região norte de Portugal, pertence ao distrito de Aveiro e é integrada à Área Metropolitana do Porto, assim como a sub-região NUTS III, Entre Douro e Vouga (Figura 2), com 21.762 habitantes numa área de 8,11 km², sendo, portanto, o menor município português. É composto por 21 bairros, quais sejam: Casaldelo, Corgas, Carquejido, Espadanal, Fundo de Vila, Fundões, Fontaínhas, Laranjeiras, Mourisca, Orreiro, Parrinho, Pedaço, Ponte, Praça, Quintã, Ribeiros, Tapado, Travessas, Vale, Vista Alegre e Volta (Câmara Municipal de SJM).

\section{Figura 2}

\section{Localização de São João da Madeira}

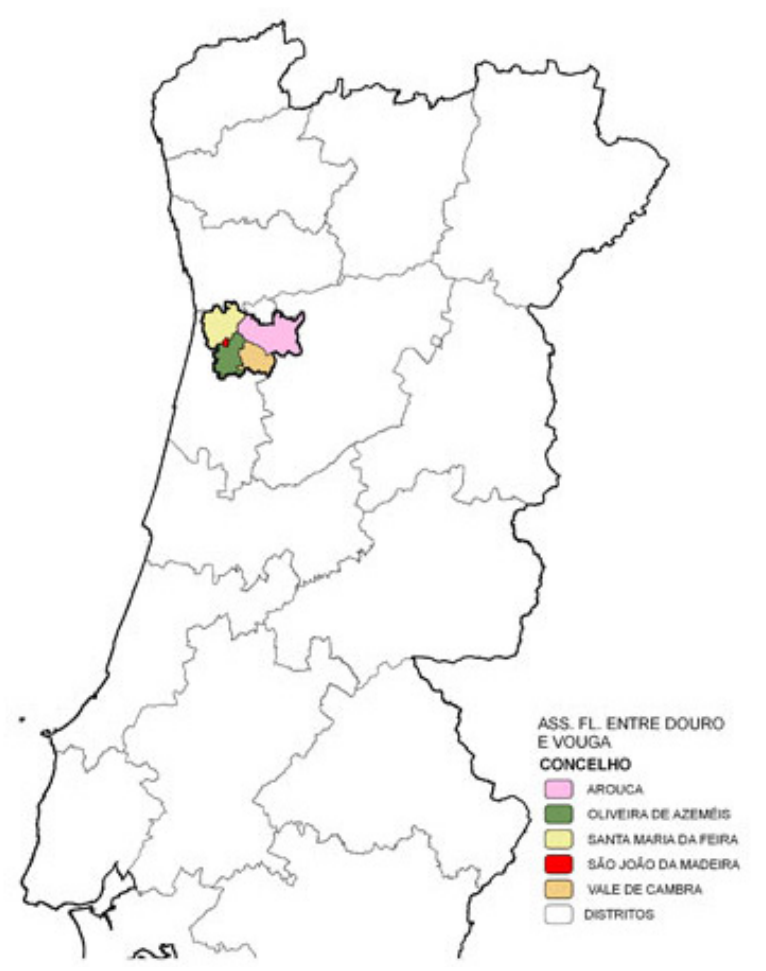

fonte: Disponível em: <http://www.google.com.pt>. Acesso em: 18 abr. 2012. 
município teve grande desenvolvimento no século XIX, sobretudo com a instalação da fábrica de chapéu e em seguida pela indústria de calçado. $\bigcirc$ início da fabricação de calçados na cidade remonta os anos de 1483. A primeira fábrica de calçado, "sapataria da moda", surgiu por volta de 1833, em 1905 surge outra e já em 1910 são registradas quatro oficinas em Oliveira de Azeméis, município do qual São João da Madeira fazia parte (Câmara Municipal de São João da Madeira). A forte tradição na área industrial, designadamente na área do calçado, possibilitou à cidade a ocupação de um lugar de destaque no mapa empresarial português, sendo detentora da marca "Capital do Calçado" (www. cidades.vidaimobiliaria.com).

De acordo com o Plano Estratégico de Desenvolvimento Local de 2009 (PEDL) de São João da Madeira, há no município quatro áreas industriais, embora se destaquem a zona industrial das travessas e a zona industrial do Orreiro, as quais, tal como a zona industrial de Devesa velha, estão localizadas perifericamente em relação à área mais urbanizada, sendo dotadas de espaços amplos com grande acessibilidade e com uma cintura verde envolvente que minimiza o seu impacto em termos ambientais. Permanece ainda, dentro do perímetro mais urbanizado, a zona industrial de Oliva, com uma forte redução de atividades e, consequentemente, do seu impacto ambiental.

Para verificarmos como ocorre a produção do calçado em nível individual de indústria, pesquisamos duas delas no município, uma média e uma pequena. Essas duas indústrias se encontram localizadas na Zona Industrial do Orreiro. Para facilitar o entendimento e a visualização dos dados obtidos por meio do questionário respondido pelas indústrias, verifiquem a Tabela 2:

\section{Tabela 2}

\section{Características das indústrias pesquisadas}

\begin{tabular}{lll}
\hline Características & Indústria média & Indústria pequena \\
\hline ano de fundação & 1970 & 1993 \\
\hline no funcionários & 87 & 15 \\
\hline produção & marca própria & marca própria e de clientes \\
\hline destino geográfico & mercado externo 95\% & mercado externo 98\% \\
\hline & mercado interno 5\% & mercado interno 2\% \\
\hline venda do calçado & atacado & atacado e varejo \\
\hline exportações & representantes e venda direta & representantes e agentes de importação \\
\hline participação em feiras & participa de 6 feiras no ano & não participa \\
\hline setor de design & tem & não tem \\
\hline $\begin{array}{l}\text { liberdade de criação de } \\
\text { novos modelos }\end{array}$ & tem em todos os mercados & tem apenas no mercado interno \\
\hline
\end{tabular}

fonte: Questionário direto, 2012. Organizada pela autora.

Como pode ser verificado na Tabela 2, as duas indústrias estão a mais de 15 anos no mercado; porém, a de pequeno porte atua mais recentemente, talvez isto explique a sua desvantagem em relação àquela de médio porte, no tocante a alguns fatores, como por exemplo, a necessidade de ainda 
fabricar calçados com marca de clientes, não possuir liberdade de criação de novos modelos. Porém, ao atentarmos para a questão de design, percebemos que a pequena não investe na criação de um setor dentro da empresa que seja responsável pela criação de novos designs. Esse tipo de investimento é indicado pelo Plano Estratégico para o setor, como meio de desenvolvimento da indústria, além disso, não há participação em feiras, eventos que, de acordo com a Apiccaps e com representante da média empresa, é estratégia de publicidade para a indústria, assim como possibilita o contato com novos clientes e mercados, podendo ser formalizadas algumas vendas. Para a indústria que ainda não possui marca forte no mercado, a participação neste tipo de evento é de suma importância, devido à apresentação de sua marca e de seus novos modelos.

$\bigcirc$ destino geográfico, no mercado externo das duas indústrias, é na maior parte os países europeus, sendo que a indústria de médio porte já conseguiu adentrar, de forma discreta, o mercado dos Estados Unidos. De acordo com seu representante, há a intenção da indústria de aumentar sua atuação neste mercado.

$O$ destino geográfico no mercado interno, apesar de ser pouco representativo nas duas indústrias, constitui-se nas cidades maiores como Lisboa, Porto, Braga, Faro, Évora, entre outras e o próprio município, pela facilidade de acesso dos comerciantes locais ao fabricante.

Nenhuma das indústrias pesquisadas possui loja de fábrica, o comércio é realizado apenas por comerciantes que atuam na venda a varejo; porém, a pequena indústria realiza a venda a varejo, direto na fábrica, embora este tipo de comércio não possua muita relevância em seu volume de venda. Acreditamos que tal característica é comum a quase todas as indústrias de São João da Madeira, pois observando a paisagem urbana do município não identificamos a presença de nenhuma loja de fábrica.

Percebemos, por meio do questionário respondido pelas duas indústrias de São João da Madeira e pelos dados obtidos na Apiccaps, que apesar do grande incentivo à exportação e $95 \%$ da produção de calçados de Portugal destinar-se ao mercado externo, este ainda se mantém regionalmente, ou seja, é restrito ao mercado comunitário, atingindo em pequena porcentagem os mercados extracomunitários.

\section{O comércio de calçados em São João da Madeira (PT)}

Os dados utilizados para análise do comércio de calçados de São João da Madeira foram obtidos por meio de questionários aplicados aos gerentes dos estabelecimentos comerciais.

No que se refere à localização e distribuição de atividades, em São João da Madeira verificase uma nítida concentração de comércio e serviços na zona central e nas principais artérias de acesso a esta zona; há também certa concentração de atividades na Rua do Brasil, na Avenida Dr. Renato Araújo, na rua João de Deus e na avenida Benjamin Araújo.

Procuramos identificar na cidade os estabelecimentos comerciais na área central e em seus arredores, os quais chegaram a oito, um dos quais se localiza em um pequeno centro comercial, na praça central da cidade, com apenas uma funcionária, que divide a função de vendedora com a proprietária da loja.

Além dos estabelecimentos da área central e de seu entorno, identificamos mais seis unidades comerciais, instaladas no centro comercial, "8a Avenida", sendo este de dimensões não compatíveis com o tamanho da cidade e contando com a presença de uma grande rede de hipermercado, o "Continente". Questionados sobre a relação da dimensão do centro comercial com o número de 
habitantes da cidade, fomos informados, pelos comerciantes, que este centro comercial atende tanto os moradores locais como os das cidades da região, como São Roque, Arrifana, Santa Maria da Feira, Olivais de Azeméis, Vale de Cambra, Ovar, Lourosa, Estarreja etc.

Dos seis estabelecimentos comerciais, especializados no comércio varejista de calçados e instalados no Centro Comercial "8a Avenida", dois são lojas de fábrica de outros países, Brasil e Espanha, um estabelecimento comercializa apenas calçados importados, pelo que fomos informados e pelos calçados que vimos expostos, inferimos que a maioria dos calçados são sintéticos; porém, seus representantes não quiseram responder ao questionário. Dessa forma, aplicamos questionários em três estabelecimentos do Centro Comercial, que somados àqueles localizados nas ruas centrais e àquele localizado no pequeno centro comercial da praça principal, totalizaram 11 estabelecimentos pesquisados.

Dos estabelecimentos pesquisados, 54\% comercializam calçados masculinos e femininos, e $45 \%$, além desses dois modelos, comercializam também modelos infantis. A maioria (72\%) comercializa somente calçados produzidos à base de couro.

Todos os estabelecimentos pesquisados comercializam calçados produzidos em São João da Madeira. Dois comercializam somente calçados de produção local e nove comercializam mais de 60\% de calçados de São João da Madeira.

Verificamos, por meio dos dados, que a produção local é valorizada e possui grande importância para o comércio varejista especializado no calçado, embora ainda se encontrem estabelecimentos que comercializam calçados de outras localidades. Dentre as áreas geográficas de origem dos calçados comercializados nesses estabelecimentos encontram-se Itália, Espanha, China, Brasil, Indonésia e Marrocos, este último foi citado apenas por um estabelecimento e a Espanha foi por quatro. Tais dados reforçam a questão da Espanha ser o principal parceiro comercial de Portugal.

Quase 100\% dos estabelecimentos utilizam representantes nas compras de calçados produzidos em outros países e pedido direto ao fabricante nas compras das indústrias locais. Os comerciantes valorizam o calçado de produção local, mas não lhes são oferecidas vantagens pelos industriais; mesmo assim, acreditam que comercializar os calçados de produção local tem suas vantagens, primeiro pelo custo do transporte, por ser de alta qualidade e pela garantia do produto.

contato com os comerciantes locais proporcionou-nos obter a informação de que eles acreditam que os industriais de São João da Madeira são conservadores e não se direcionam em busca de inovação. Essa informação vai de encontro ao que foi especificado anteriormente, ou seja, de que há uma ausência de espírito empreendedor entre os fabricantes de São João da Madeira.

A leitura das bibliografias que tratam das indústrias do setor de calçados apontam para a importância das feiras, principalmente aquelas de âmbito internacional, como um espaço de propaganda e de formalização de negócios, assim como espaço de obtenção de informação sobre as tendências de moda, porém apenas quatro dos comerciantes questionados participam de feiras do setor, sendo as mais citadas, Milão, Madrid, Berlim, Dusseldorf, sendo que a de Milão se sobressai, pois os comerciantes que participam de outras feiras também participam desta.

Os gerentes dos quatro estabelecimentos que disseram participar das feiras colocaram como motivação para a participação nestes eventos a realização de compras de calçados de origem estrangeira e a obtenção de informações sobre as novidades do setor. Este dado comprova o que traz a bibliografia de que as feiras são espaços de formalização de negócios e atualização sobre as tendências de moda. 
Diante da baixa participação dos estabelecimentos nas feiras do setor, a maioria é informada sobre os novos modelos e as novas coleções no momento da realização da compra para o abastecimento da loja ou por intermédio de representantes, que trazem o mostruário e o catálogo com os novos modelos.

Atualmente, o lojista não pode contar com a fidelidade do consumidor, pois a diversidade de produtos, com diferentes preços, assim como diferentes espaços de consumo, gera uma gama de opções. Dessa forma, o lojista deve adotar estratégias de propaganda e marketing para atrair o consumidor. Mesmo com a importância de tais estratégias na atualidade, apenas seis dos 11 estabelecimentos pesquisados investem em propaganda, sendo que três a realizam por meio da internet e os outros três que se localizam no Centro Comercial, o "8a Avenida", fazem a propaganda por intermédio do centro comercial, geralmente em sites.

Após identificarmos as características da produção e do comércio de calçados em São João da Madeira, procedemos a verificação de como se estabelece a articulação entre a produção e o comércio de calçados de produção local

\section{A articulação entre produção e comércio de calçados em São João da Madeira (PT)}

Por meio da aplicação do questionário aos gerentes dos estabelecimentos comerciais e de algumas informações extras conseguidas junto aos mesmos, assim como a visita a campo, conseguimos caracterizar os estabelecimentos e verificar a relação existente entre o comerciante e o fabricante de calçado.

Foi possível perceber que as novas formas espaciais de comércio, bem como as novas estratégias de venda convivem com as antigas, pela presença do Centro Comercial "8a Avenida", onde os comerciantes aproveitam do diferencial do espaço destinado ao consumo para atrair os consumidores, pois como nos coloca Cleps (2005, p. 47) estes constituem em "novas formas de se realizarem as trocas, são considerados como objetos sociais que, onde se instalam, provocam mudanças estruturais e alteram o cotidiano das pessoas que são convidadas a consumir".

Não encontramos nenhum outlet que comercialize marcas dos fabricantes locais, não visualizamos nenhum outdoor pela cidade e nem tampouco nas vias de acessos que indique a presença das indústrias ou dos estabelecimentos comerciais, especializados no comércio de calçados. Isto pode indicar que não há preocupação com o city marketing da cidade, ou seja, com sua divulgação de capital nacional do calçado, contudo ela é divulgada no site oficial da Câmara Municipal. Verificamos que a importância da produção de calçado em São João da Madeira não está refletida em seu espaço urbano, dessa forma um viajante que passe pela cidade não terá a percepção imediata da atividade ali desenvolvida. Só tem este conhecimento os moradores e as pessoas que sabem de sua história, de sua tradição.

Apesar de não haver a divulgação de seus calçados, percebemos que há uma grande valorização da mercadoria produzida localmente pelos estabelecimentos de comércio do local, mesmo com a produção sendo muito mais direcionada para o mercado externo, pois todos os comércios pesquisados possuem em seu estoque mais de 60\% de calçados produzidos no município.

No que se refere à relação comerciante e produtores, verificamos, em São João da Madeira, que a interlocução entre ambos tem pouco espaço para sua realização. Os novos modelos são criados e apresentados aos comerciantes apenas no momento da realização da compra, para abastecimento 
da loja, inclusive um dos gerentes afirmou-nos que gosta muito de dizer o que deseja para a sua loja, mas tem pouca oportunidade para isso, pois, de acordo com ele, os fabricantes não lhes dão muita abertura. Percebemos que não há uma forte relação entre fabricante e comerciante e que ambos estão perdendo oportunidade de utilizar um importante meio de conhecer o consumidor e de contribuir para a inovação do produto, ficando toda a tarefa para o agente responsável pelo design na hora do desenvolvimento dos novos modelos.

\section{Considerações finais}

Os resultados e a análise desenvolvida nesta pesquisa podem concorrer para despertar novos interesses pelo tema abordado. Estudos acadêmicos sobre aglomerados produtivos com o foco proposto aqui são de grande relevância, pois as concentrações geográficas de indústrias têm chamado a atenção de pesquisadores de diversas áreas, sobretudo no âmbito da geografia. Como é um tema de recente interesse, ainda há muito a ser investigado para compreender, de forma abrangente, esse tipo de arranjo produtivo e as questões socioespaciais que suscita.

Acreditamos que, à medida que surjam estudos sobre o tema, novas ferramentas estarão disponíveis às instituições de apoio dos aglomerados produtivos e aos representantes do poder local, para que atuem decisivamente em seu desenvolvimento e, dependendo da vontade política dos envolvidos, até mesmo no desenvolvimento socioespacial do município onde está o aglomerado.

A abordagem deste estudo servirá tanto para enriquecer o conhecimento científico quanto para subsidiar agentes de governança dos aglomerados produtivos, pois ressalta a importância de os fabricantes começarem a se preocupar com a cadeia de valor, mantendo estreitas relações com os responsáveis pela criação, design e comercialização dos produtos. Além disso, estudos desta natureza são importantes porque evidenciam as fragilidades do aglomerado produtivo.

\section{Referências}

ASSOCIAÇÃO PORTUGUESA DOS INDUSTRIAIS DE CALÇADOS, COMPONENTES E ARTIGOS DE PELE E SEUS SUCEDÂNEOS - Apiccaps. Monografia estatística. Porto, 2011.

BARATA SALGUEIRO, T.; CACHINHO, H. As relações cidade-comércio: dinâmicas de evolução de modelos interpretativos. Apontamentos de Geografia, Lisboa: Centro de Estudos Geográficos, n. 20, 2006. (Série Investigação.)

BAUDRILLARD, J. A sociedade de consumo. Lisboa: 1981.

CACHINHO, H. O comércio retalhista português: pós-modernidade, consumidores e espaço. Lisboa: Gepe/Ministério da Economia, 2002.

CARREIRAS, C. Consumir ou comprar: repensando o consumo urbano à luz da globalização. GEOUSP - Espaço e Tempo, n. 6, p. 81-94, 1999.

CLEPS, G. D. G. Estratégias de reprodução do capital e as novas espacialidades urbanas: o comércio de autosserviço em Uberlândia (MG). Tese (Doutorado em Geografia) - Instituto de Geociências e Ciências Exatas, Universidade Estadual Paulista Júlio de Mesquita Filho, Rio Claro, 2005. 
EIRIZ, V.; BARBOSA, N. Interação entre redes organizacionais locais. Estudos Regionais, n. 16, 2007. Disponível em: <www.apdr.pt/siteRPER/numeros/RPER16/16.2.pdf>. Acesso em 14 fev. 2012.

FONSECA et al., 2001.

GARCIA, J. R.; COSTA, A. J. D. Sistemas produtivos locais: uma revisão da literatura, 2005. Disponível em: <www.unifae.br/publicacoes/pdf/Ilseminario/iniciacaoCientifica/iniciacao_09.pdf>. Acesso em: 20 jan. 2012.

MAIA, K. Confecções em Cianorte: um distrito industrial? Economia, Curitiba, n. 19. p. 137176, 1995.

MENDES, A. A. Reestruturações locais como efeitos da globalização econômica: uma análise da estrutura produtiva mutante do polo têxtil de Americana-SP. Tese (Doutorado em Geografia) - Instituto de Geociências e Ciências Exatas, Universidade Estadual Paulista Júlio de Mesquita Filho, Rio Claro, 1997.

PINHEIRO, S. S. Relações de produção e trabalho: uma análise geográfica da indústria de vestuários, calçados e artefatos de tecido em Rio Claro-SP e suas vinculações espaciais. Dissertação (Mestrado em Geografia) - Instituto de Geociências e Ciências Exatas, Universidade Estadual Paulista Júlio de Mesquita Filho, Rio Claro, 1993.

PINTAUDI, S. M. Os supermercados na Grande São Paulo: contribuição ao estudo da transformação do comércio varejista de gêneros alimentícios nas grandes metrópoles. Dissertação (Mestrado em Geografia) - Faculdade de Filosofia, Letras e Ciências Humanas, Universidade de São Paulo, São Paulo, 1981.

ROVERE, R. As pequenas e médias empresas na economia do conhecimento: implicações para políticas de inovação. REDESIST - Informação e Globalização na Era do Conhecimento, 1999. Disponível em: <http://www.sinal.redesist.ie.ufrj.br/dados/nt_count. php? projeto=LvllEcod=8>. Acesso em: 15 maio 2010.

VALE, M.; CALDEIRA, J. Proximity and Knowledge Governance in Localized Production Systems: The Footwear Industry in the North Region of Portugal, European Planning Studies, v. 15. n. 4, p. 531-548, apr. 2007. Disponível em: <http://dx.doi. org/10.1080/09654310601134854> Acesso em: 18 jan. 2012. 